\title{
Application of Polynomial Rocking Bearings as Seismic Isolation System on Irregular Bridges
}

\author{
Krisna Febrian Anugerahputra ${ }^{1}$, Lee Tzu Ying ${ }^{2}$, Ari Wibowo ${ }^{1}$ \\ ${ }^{1}$ Civil Engineering Department, Engineering Faculty, Universitas Brawijaya, Malang, \\ 65145, Indonesia \\ ${ }^{2}$ Civil Engineering Department, Engineering Faculty, National Central University, \\ Taoyuan City, 32001, Taiwan \\ krisfebrian9132@gmail.com
}

Received 18-11-2017; revised 18-01-2018; accepted 14-02-2018

\begin{abstract}
Friction Pendulum System (FPS) is one of the conventional sliding isolators which widely used and effectively proved to reduce seismic hazard in far-fault earthquakes. However, it may not be effective when the structures are induced by near-fault earthquakes because the earthquake's period is usually close to the isolation period. In this study, a Polynomial Rocking Bearing (PRB) which has variable isolation stiffness is used to improve the performance of seismic isolation systems applied on irregular bridges under near-fault earthquakes. The PRB is composed by an articular joint and concave rocking surface. The rocking surface is defined by a sixth-order polynomial function. Based on previous studies, the PRB has been verified to effectively suppress the large isolator displacement subjected to near-fault earthquakes on building and regular bridges. However, it has not been used yet in the irregular bridges. This study aims to analyze the behaviour of Polynomial Rocking Bearing installed on an irregular bridge. As compared with Friction Pendulum Systems (FPS), the performance of PRBs is much better to effectively suppress the displacement of the bridge deck in both near and far-fault earthquakes.
\end{abstract}

Keywords: irregular bridges, near-fault earthquakes, polynomial rocking bearing, variable isolation stiffness.

\section{Introduction}

Bridges are one of the most vital components in the transportation system. Design of bridges are based on its function, ground condition, material construction, and the available funds. No matter what kinds of bridges will be constructed, they must be able to carry any loads especially seismic loading to provide safety and comfort for users. In the past extreme earthquakes, a number of bridges suffered serious damage. Once bridges failure or collapse, it will impede recovery and rehabilitation.

To protect bridges from seismic damage, bridges should be designed based on the bridge seismic design codes. A modern technique of mitigating seismic damage is called structural control. Structural control can be classified into three, passive, active, and semi-active control. More than 20 years, most of the previous researchers use passive control, especially base isolation systems or seismic isolation systems $[1,2,3,4,6,9]$. 
Seismic isolation systems are usually placed between structure and foundation on buildings. The main concept of this technology is to increase the fundamental period of structures and/or dissipate the seismic energy transmitted directly onto the structure systems [10]. Seismic isolators can be divided into two groups, namely, sliding bearings and elastomeric bearings $[5,7,11]$. Friction Pendulum System (FPS) is commonly-used sliding bearings. Previous research has shown that the FPS has good isolation effect when structures are subjected to far-fault earthquakes. However, it may result in an excessive isolator displacement under near-fault earthquakes.

To overcome this problem, some researchers suggested the isolation systems with variable mechanical properties, which may be adaptive to a wider range of earthquakes. Polynomial Rocking Bearings (PRBs) proposed by $\mathrm{Lu}$ et al. [8] has variable mechanical properties. In the previous study, Polynomial Rocking Bearing has applied on the building by $\mathrm{Lu}$ er at [8] and also applied to the regular bridge (bridge with the same heights of the column). Based on both previous researches, Polynomial Rocking Bearing (PRBs) is able to effectively suppress the large isolator displacement induced by strong near-fault earthquake.

Bridges structure may be irregular in column heights due to complex terrain, route alignment, ramps, interchanges, and so on. In this study, PRBs are installed between the deck and the column of the irregular bridge. This research is aimed to analyze the behaviour of Polynomial Rocking Bearing installed on an irregular bridge subjected to the seismic loading. The optimum parameters of PRBs are found out using PSO-SA hybrid searching algorithm. Lastly, the seismic performances of the irregular bridge with PRBs and FPS are compared to verify the superiority of PRBs.

\section{Material and Methods}

\subsection{Configuration of PRBs}

Polynomial Rocking Bearing (PRB) is an axially symmetric rocking surface with variable curvature. It has an articular (ball and socket) joint on the upper part and a concave rocking surface with a base plate on the lower part [8]. The articular joint is mounted on the footing of the superstructure, while the base plate is mounted on the foundation [8]. When the earthquake occurred, the rocking surface of the bearing will rock back and forth on the base plate, thus provide an isolation layer to reduce the ground motion transmitted into the super-structure.

PRB is one of the seismic isolation systems. It can mitigate the seismic load transmitted onto the structure, so the structural systems and their facilities inside will be safe. Based on Figure 1, PRB has three design parameters: height of bearing $(\mathrm{h})$, the radius of the spherical head $(\mathrm{r})$, and the geometrical function of rocking surface $Y=G(X)$. In this study, the sixth-order polynomial function is chosen to make the bearing with variable stiffness.

$$
G(X)=c_{1} X^{6}+c_{2} X^{4}+c_{3} X^{6}
$$

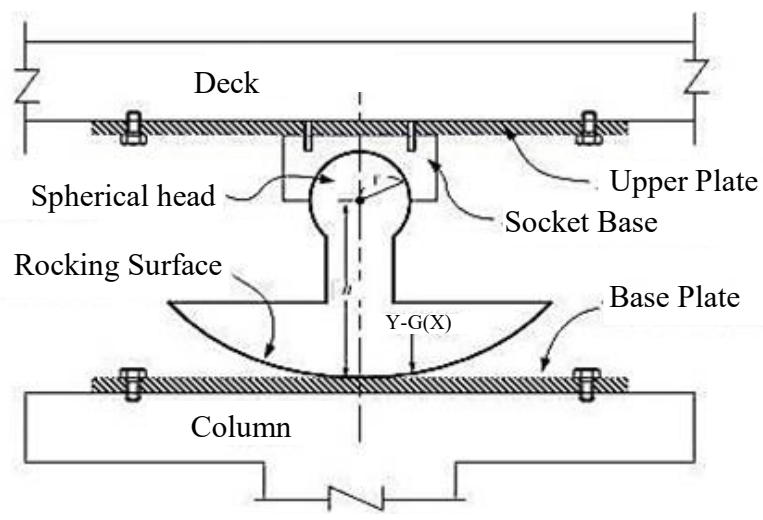

Figure 1. Polynomial rocking bearings installed under bridge's deck. 


\subsection{Horizontal Restoring Force of PRB}

Besides the configuration, the mechanical properties of an isolator are also important things. Before discussing mechanical properties, for simplicity, some assumptions will be made. First, rocking surface and base plate of bearing should have a point contact anytime. Second, the friction coefficient between them should be large enough to prevent slippage. Third, the inertial moment due to the rocking motion is negligible as compared to the forces applied to the bearing. At last, the radius of curvature should be larger than height to retain stability.

Based on Figure 2, there are two coordinate systems on this isolator, $x-y$ and $X-Y$. The $x-y$ is a fixed coordinate system which $\mathrm{X}$-axis attached to the ground. The $\mathrm{X}-\mathrm{Y}$ is moving coordinate system of PRB attached to bearing and will rock along the bearing. Therefore, when the bearing is on its origin position, both of the coordinate systems coincides each other. However, when the systems are rocking, there will be a rotation angle between $x-y$ and $X-Y$ that denoted by $\theta_{\mathrm{a}}$. Since it assumed that the rocking surface of $\mathrm{PRB}$ has a point contact with ground, so the $\mathrm{x}$-axis is tangent to the contact point $\mathrm{A}$.

$$
\tan \theta_{a}=\frac{\sin \theta_{a}}{\cos \theta_{a}}=G^{\prime}\left(X_{a}\right), \quad-\frac{\pi}{2} \leq \theta_{a} \leq \frac{\pi}{2}
$$

$\theta_{\mathrm{a}}$ denotes rotation angle, while $\mathrm{X}_{\mathrm{a}}$ denotes moving coordinate for contact point. Other parameters are four forces that work on the isolator. $\mathrm{W}$ is the structural weight, $\mathrm{U}$ is the horizontal resultant forces, $\mathrm{N}$ is the normal forces at contact point $\mathrm{A}$, and $\mathrm{F}$ is the friction forces at contact point $\mathrm{A}$. W and $\mathrm{U}$ are actually the forces that occur between superstructure and the bearing. Moreover, the force $U$ as horizontal resultant forces transmitted onto isolated structure is an important parameter. The force $\mathrm{U}$ is defined by taking the moment equilibrium at contact point $\mathrm{A}$ and written as follows:

$$
\begin{aligned}
& \sum F_{x}=0 \rightarrow U=F \\
& \sum F_{y}=0 \rightarrow W=N \\
& \sum M_{A}=0 \rightarrow U=u_{r}=\frac{W\left(x_{a}-x_{b}\right)}{y_{b}}
\end{aligned}
$$

W denotes structural weight, $\mathrm{U}$ denotes horizontal resultant forces, $\mathrm{N}$ and $\mathrm{F}$ represents normal forces and friction forces at contact point $\mathrm{A}$, respectively, $u_{r}$ denotes bearing restoring force, $\mathrm{x}_{\mathrm{a}}$ denotes $\mathrm{x}$ coordinate of the contact point $\mathrm{A}$ in the $\mathrm{x}-\mathrm{y}$ coordinates, while $\mathrm{x}_{\mathrm{b}}$ and $\mathrm{y}_{\mathrm{b}}$ are $\mathrm{x}$ and $\mathrm{y}$ coordinates of the point $\mathrm{B}$, respectively.

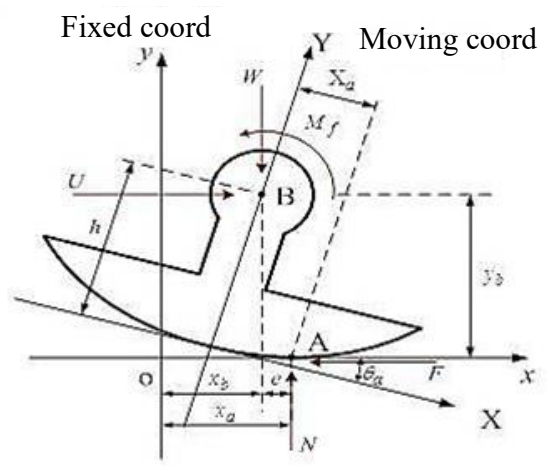

Figure 2. Free body diagram of polynomial rocking bearings

Since it assumed that friction coefficient between the rocking surface and base plate should be large enough to prevent slippage, so $x_{a}$ should be equal to the arc length $\left(S_{a}\right)$ between $A$ and centre axis of moving coordinate system. 


$$
x_{a}=S_{a}=\int_{0}^{X_{a}} \sqrt{1+G^{\prime}\left(X_{a}\right)^{2} d X}
$$

Using the coordinate transformation relation between $\mathrm{x}-\mathrm{y}$ and $\mathrm{X}-\mathrm{Y}$ systems, the value of $\mathrm{x}_{\mathrm{b}}$ and $\mathrm{y}_{\mathrm{b}}$ can be determined as:

$$
\begin{aligned}
& x_{b}=\left(h-G\left(X_{a}\right)\right) \sin \theta_{a}-X_{a} \cos \theta_{a}+x_{a} \\
& y_{b}=\left(h-G\left(X_{a}\right)\right) \cos \theta_{a}+X_{a} \sin \theta_{a}
\end{aligned}
$$

Refer to equation 2, with eliminating variable $\theta_{\mathrm{a}}$, the value of $\mathrm{x}_{\mathrm{b}}$ and $\mathrm{y}_{\mathrm{b}}$ can be determined in another form.

$$
\begin{aligned}
x_{b} & =S_{a}+\frac{-X_{a}+\left(h-G\left(X_{a}\right)\right) G^{\prime}\left(X_{a}\right)}{\sqrt{1+G^{\prime}\left(X_{a}\right)^{2}}} \\
y_{b} & =\frac{X_{a} G^{\prime}\left(X_{a}\right)+\left(h-G\left(X_{a}\right)\right)}{\sqrt{1+G^{\prime}\left(X_{a}\right)^{2}}}
\end{aligned}
$$

From the equations above, variables $\mathrm{x}_{\mathrm{a}}, \mathrm{x}_{\mathrm{b}}$, and $\mathrm{y}_{\mathrm{b}}$ are depend on variable $\mathrm{X}_{\mathrm{a}}$ which represents the $\mathrm{X}$ coordinate of the contact point A. Refer to equation 5, equation 6 , equation 9 , and equation 10 , the existence of restoring force ur can be shown as:

$$
u_{r}=u_{r}\left(X_{a}\right)=\frac{W\left[-\left(h-G\left(X_{a}\right)\right) G^{\prime}\left(X_{a}\right)+X_{a}\right]}{\left(h-G\left(X_{a}\right)\right)+X_{a} G^{\prime}\left(X_{a}\right)}
$$

Thus, to express the restoring force $u$ r of Polynomial Rocking Bearing, it should be defined first about the geometric function of Polynomial Rocking Bearing.

\subsection{Horizontal Friction Force of PRB}

Since the spherical head of Polynomial Rocking Bearing has the friction effect, it will provide the energy dissipation of the bearing. So, when the friction is considered, the behavior of spherical head will change like the Figure 3. This figure represents the resultant friction force and resultant normal force with the symbol $\mathrm{F}$ and $\mathrm{N}$, respectively. For the resultant normal force, because it measured from the vertical axis, so there will be an angle $\phi$. Note that the force $\mathrm{N}$ and $\mathrm{F}$ are perpendiculars each other.

For the convenience, the force system in the Figure $3 \mathrm{a}$ is slightly replaced by the equivalent calculation of force system in the Figure $3 b$, in which $\mathrm{W}$ and $\mathrm{U}$ are the equivalents vertical and horizontal force components. The Force $\mathrm{W}$ and $\mathrm{U}$ are interactive forces between the structure and bearing, so it should be affected by the structural weight and dynamic response. Furthermore, in the Figure $3 \mathrm{~b}$, the equivalent couple moment produce by friction force $\mathrm{F}$ to point $\mathrm{B}$ can be expressed as:

$$
M_{f}=r F
$$

$M_{f}$ denotes moment produce by $F$.

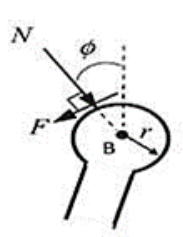

(a) Original

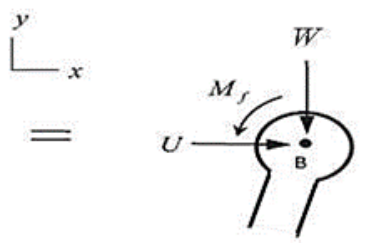

(b) Equivalent

Figure 3. Equivalent force Systems at spherical head of PRBs 
From the Figure 3, it is assumed that the bearing has a positive displacement and its rocking outward (the articular joint moving away from the neutral position). If the bearing has the opposite direction, so the directions of $\mathrm{F}$ and $\mathrm{M}_{\mathrm{f}}$ should be reversed.

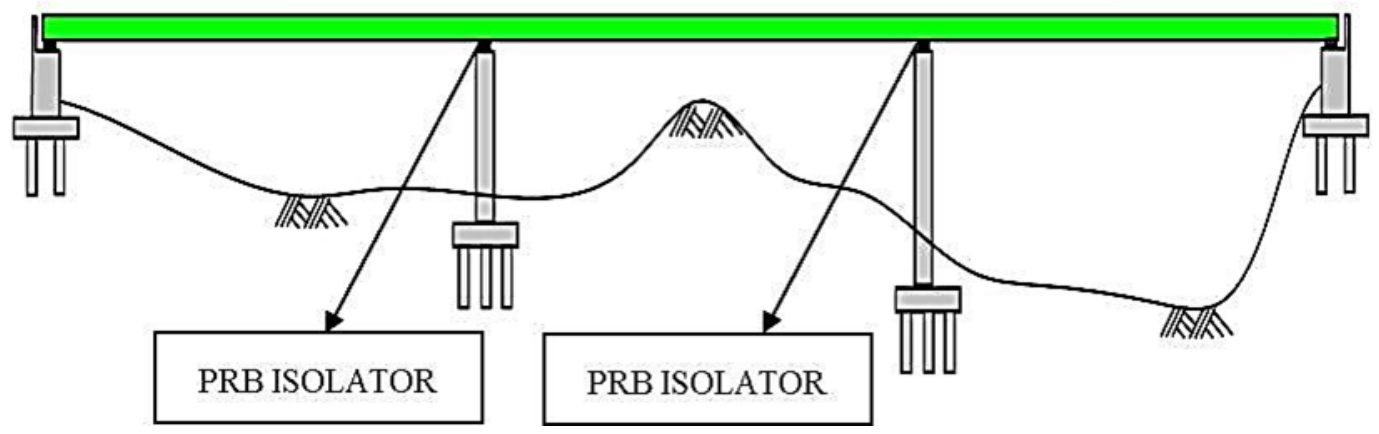

Figure 4. Model of Target Bridges

Generally, the directions of $\mathrm{F}$ and $\mathrm{M}_{\mathrm{f}}$ should be determined by the rocking direction of the bearing, once it moving outward or inward. Horizontal force $\mathrm{U}$ is consisting of restoring force and friction force.

$$
\begin{aligned}
& U=u_{r}+u_{f} \\
& u_{r}=\frac{W e}{y_{b}}=\frac{W\left(x_{a}-x_{b}\right)}{y_{b}} \\
& u_{f}=\frac{M_{f}}{y_{b}}=\frac{r F}{y_{b}}
\end{aligned}
$$

\subsection{Analysis Model and Method}

\subsubsection{Design of Target Bridge}

The bridge is designed based on the Japan Highway Bridge Design Codes. As shown in the Figure 4 , the bridges consist of the three-span deck with two abutments and two different heights of columns. The detail parameters are shown in the Table 1. This study is based on single span bridge deck with a different height of the column. The following assumption is considered to simplify the analysis. First, the soil condition along the bridge is uniform. Second, the vertical ground motion characteristics of the structure are not considered. Third, the friction coefficient of the bearing is constant. Lastly, the maximum static friction coefficient is equal to its dynamic friction coefficient.

\subsubsection{Equation of Motion Derivation}

From the free body diagram as shown in the Figure 5, the bridge's system will divide into two parts, upper part and lower part. The upper part is a bridge's deck, and the lower part is bridge's column.

$$
\begin{aligned}
& m_{d} \ddot{x}_{d}=-\left(U_{1}+U_{2}\right)-m_{d} \ddot{x}_{\mathrm{g}} \\
& m_{c 1} \ddot{x}_{c 1}+c_{c 1} \dot{x}_{c 1}+k_{c 1} x_{c 1}=U_{1}-m_{c 1} \ddot{x}_{\mathrm{g}} \\
& m_{c 2} \ddot{x}_{c 2}+c_{c 2} \dot{x}_{c 2}+k_{c 2} x_{c 2}=U_{2}-m_{c 2} \ddot{x}_{\mathrm{g}}
\end{aligned}
$$

Generally, the equation of motion can be obtained as:

$$
\mathrm{M} \ddot{\mathrm{x}}(t)+\mathrm{C} \dot{\mathrm{x}}(t)+\mathrm{Kx}(t)=\mathrm{ML}_{1} \ddot{x}_{\mathrm{g}}(t)+\mathrm{L}_{2} \mathrm{U}(t)
$$

$\mathrm{M}, \mathrm{C}$, and $\mathrm{K}$ denote the mass, damping, and stiffness matrices. L1 and L2 are the seismic force distribution vector and the total horizontal force distribution matrix, respectively. $\ddot{x}_{\mathrm{g}}(t)$ is the ground excitation, $\mathrm{x}_{(\mathrm{t})}$ is structure 
displacement vector, while $U_{(t)}$ is total horizontal force vector that contains restoring force $\left(\mathrm{u}_{\mathrm{r}}\right)$ and friction force $\left(\mathrm{u}_{\mathrm{f}}\right)$.

Table 1. Parameter of Irregular Bridges

\begin{tabular}{|c|c|c|c|}
\hline \multicolumn{2}{|c|}{ Mass of Bridge's deck } & 2038.8 & ton \\
\hline \multirow{2}{*}{$\begin{array}{c}\text { Short } \\
\text { Column }\end{array}$} & $\begin{array}{l}\text { Mass of } \\
\text { column }\end{array}$ & 37.1 & ton \\
\hline & $\begin{array}{l}\text { Stiffness of } \\
\text { column }\end{array}$ & 124400 & $\mathrm{kN} / \mathrm{m}$ \\
\hline \multirow{2}{*}{$\begin{array}{l}\text { Long } \\
\text { Column }\end{array}$} & $\begin{array}{l}\text { Mass of } \\
\text { column }\end{array}$ & 74.2 & ton \\
\hline & $\begin{array}{l}\text { Stiffness of } \\
\text { column }\end{array}$ & 15740 & $\mathrm{kN} / \mathrm{m}$ \\
\hline
\end{tabular}

The equation 19 is rewritten as the state space equation of motion as follows:

$$
\dot{\mathrm{Z}}(t)=\mathrm{AZ}(t)+\mathrm{E} \ddot{x}_{\mathrm{g}}(t)+\mathrm{BU}(t)
$$

Equation 20 is a continuous-time system. It will be converted into a discrete-time system using external linear interpolation as follows:

$$
\mathrm{Z}[k+1]=\mathrm{A}_{\mathrm{d}} \mathrm{Z}[k]+\mathrm{E}_{0} \ddot{x}_{\mathrm{g}}[k]+\mathrm{E}_{1} \ddot{x}_{\mathrm{g}}[k+1]+\mathrm{B}_{0} \mathrm{U}[\mathrm{k}]+\mathrm{B}_{1} \mathrm{U}[k+1]
$$

$Z[k]$ represents the system state (contains the system velocity and displacement) and can be shown as:

$$
\mathrm{Z}[k+1]=\left[\begin{array}{l}
\dot{\mathrm{x}}[k+1] \\
\mathrm{x}[k+1]
\end{array}\right]
$$

In equation 21, $\mathbf{A}_{\mathbf{d}}$ denotes the discrete-time system matrix which contains the mass, damping, and stiffness of structure. $\mathbf{B}$ and $\mathbf{E}$ are the discrete-time matrices for the horizontal force of PRB and ground excitation, respectively. $k$ is the $k^{\text {th }}$ step and $(k+1)$ is the $\left(k^{\text {th }}+1\right)$ step, $\Delta_{t}$ is the time step.

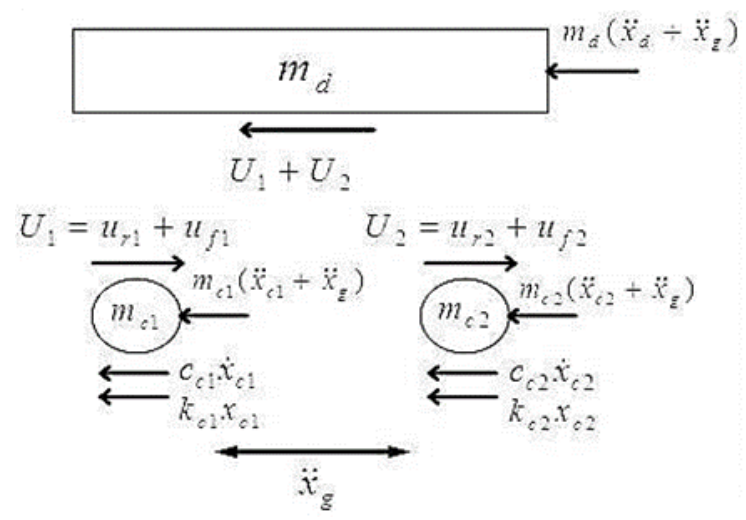

Figure 5. Free Body Diagram of Irregular Bridges

\subsubsection{Horizontal Friction Force of PRB}

The component ur that represents the restoring force can be determined by the bearing geometric parameters as shown in the previous chapter. Because the physical properties of the PRBs are complex, then the behavior of PRBs must be obtained by two coordinate systems, namely fixed coordinate system 
$(\mathrm{x}-\mathrm{y})$ and moving coordinate system $(\mathrm{X}-\mathrm{Y})$. As describe in second chapter, the value of $\mathrm{X}_{\mathrm{a}}, \mathrm{x}_{\mathrm{b}}\left(\mathrm{X}_{\mathrm{a}}\right)$, $\mathrm{y}_{\mathrm{b}}\left(\mathrm{X}_{\mathrm{a}}\right), \mathrm{x}_{\mathrm{a}}\left(\mathrm{X}_{\mathrm{a}}\right)$ are obtained by coordinate transformation systems. In this study, the bisection method is selected as the numerical solver to find $\mathrm{X}_{\mathrm{a}}$ and others parameters.

Unlike the restoring force $\left(\mathrm{u}_{\mathrm{r}}\right)$, the friction force $\left(\mathrm{u}_{\mathrm{f}}\right)$ cannot be easily expressed as an explicit function of the system response, because the friction forces have two possible states, namely sticking state and rocking state. Furthermore, because the bridge model has different height for each column, it may cause the friction force has one another possible state, namely partial rocking state. Thus, in this case, the friction force totally has three possible states: sticking state (all bearing is sticking), rocking state (all bearing is rocking), and partial rocking state (partial bearing is sticking while partial bearing is rocking). When the moment of the bearing $\left(\mathrm{M}_{\mathrm{f}}\right)$ is less than the maximum moment $\left(\mathrm{M}_{\mathrm{f}, \mathrm{max}}\right)$, it is called the sticking state. On the other hand, when the moment $\left(\mathrm{M}_{\mathrm{f}}\right)$ is equal or more than the maximum moment $\left(\mathrm{M}_{\mathrm{f} \text {,max }}\right)$, it will be in rocking state. For the detail, analysis process will be shown in the Figure 10. Moment of the bearing and the maximum moment can be shown as:

$$
\begin{aligned}
& \bar{M}_{f}[k+1]=\bar{u}_{f}[k+1] y_{b}[k+1] \\
& M_{f, \max }=\operatorname{Wrr} \beta\left(X_{a}\right)
\end{aligned}
$$

$\beta\left(X_{a}\right)$ is a modification factor to the friction coefficient.

\section{a. Sticking State}

\section{b. Rocking State}

\section{c. Partial Rocking State}

$$
\left|\bar{M}_{f}[k+1]\right|<M_{f, \max }
$$

$$
\left|\bar{M}_{f}[k+1]\right| \geq M_{f, \max }
$$

This state means at the same time, both of bearings may have different state, one is sticking state and the other is rocking state. Because the restoring force $\left(u_{r}\right)$ can be defined easily by the bearing geometric parameters, so for this condition just need to concern for the friction force $\left(u_{f}\right)$. When one of the bearings is in the sticking state, so equation 25 can be considered. And for another bearing is in the rocking state, so using equation 26.

\section{Result and Discussion}

\subsection{Ground Motion Input}

To investigate the isolation performance of PRB system on the irregular bridges, two types of horizontal ground motions with different characteristics, recorded from real earthquakes, were considered as the excitations in the simulation. Totally two ground motions are choosing to simulate the behavior of irregular bridge. For the near-fault earthquake, the 1994 Northridge Earthquake is used. To represent the far-fault earthquake, the $1940 \mathrm{El}$ Centro Earthquake is used.

\subsection{Numerical Results and Discussions}

In this study, PSO-SA hybrid searching algorithm based on Particle Swarm Optimization and Simulated Annealing is adopted to explore the optimal parameters of the PRB isolation system. PRBs have three key design parameters: the geometric function $Y=G(X)$, the bearing height $(h)$, and the radius of the spherical head (r). Thus, by properly choosing the value of these parameters, the mechanical properties of the PRBs may get the desired specifications.

Overall for the deck displacement, PRB has better isolation effect than FPS. Based on the numerical results, some figures about the structure's responses are not satisfactory, such as the hysteretic loop of the bearing. For example, is the hysteretic loop of PRB in Northridge Earthquake. Theoretically, in the short column case, the displacement of PRB in short column should be larger than longer column, because short column's stiffness is larger than longer column, so the stiffness of the bearing should be smaller than in longer bearing. However, the results show that displacement of PRB in short column is smaller than PRB in long column. It means that the stiffness of PRB in short column is larger than PRB 
in long column. This phenomenon is also occurred in the long column case. It may happened because in this research using two different analysis for the seismic isolation system and the bridge structure. Non-linear analysis is performed in the seismic isolation system while linear analysis is in the bridge structure. Nevertheless, generally, the performance of PRB isolation system is better than FPS because it can effectively suppress the deck displacement in near and far-fault earthquakes.

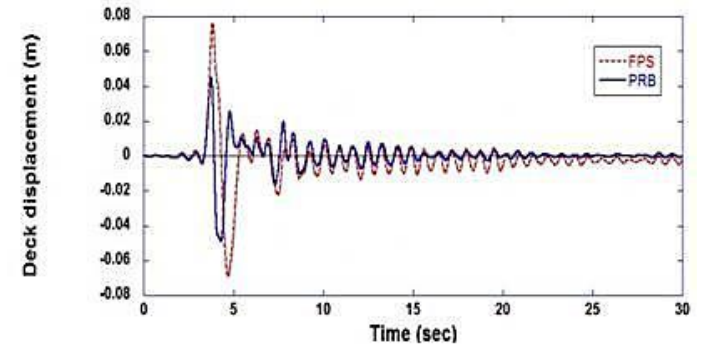

(a) Deck Displacement

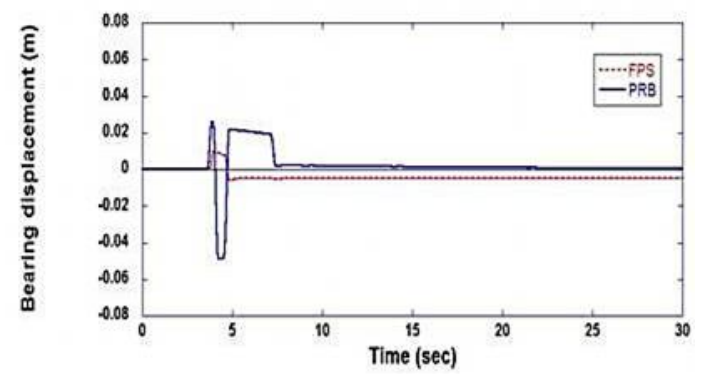

(c) Bearing Displacement in Long Column

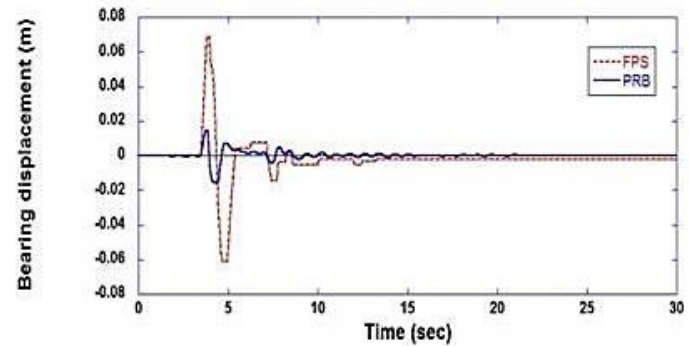

(b) Bearing Displacement in Short Column

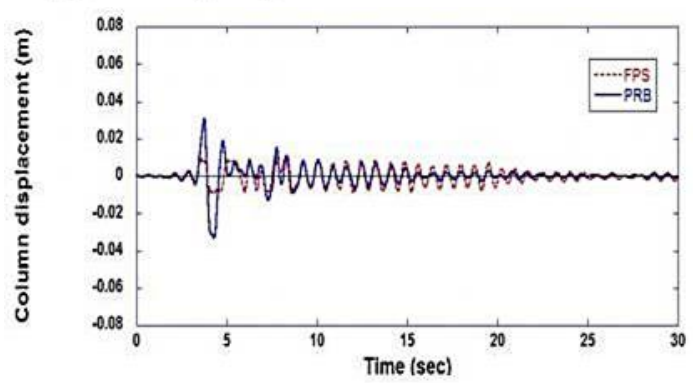

(d) Short Column Displacement

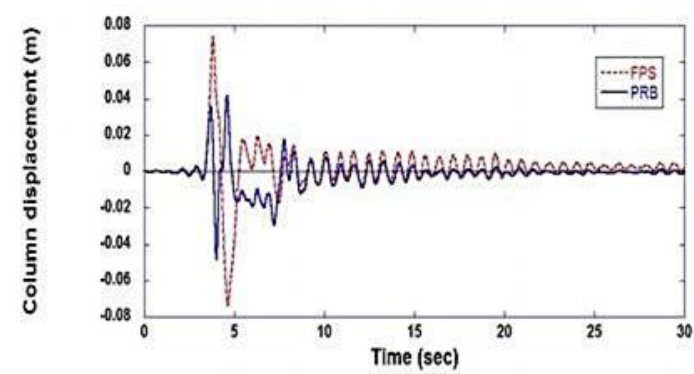

(e) Long Column Displacement

Figure 6. Time History of PRB and FPS under Northridge Earthquake

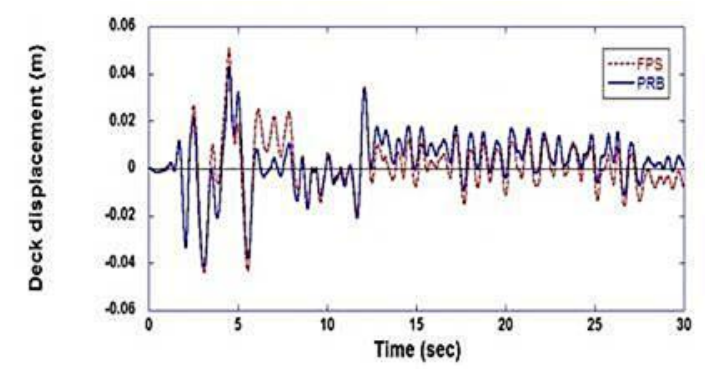

(a) Deck Displacement

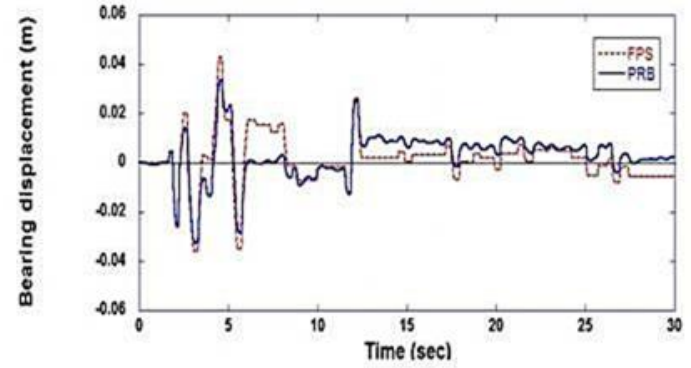

(b) Bearing Displacement in Short Column 


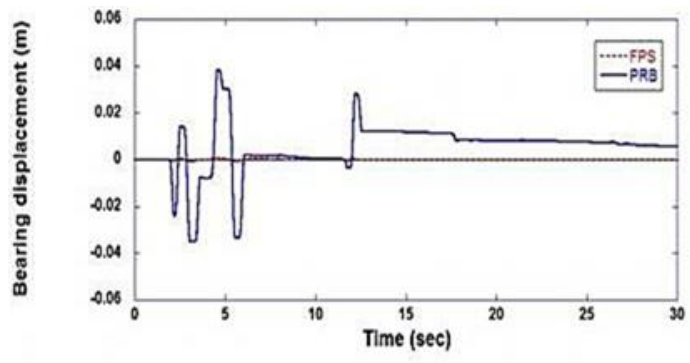

(c) Bearing Displacement in Long Column

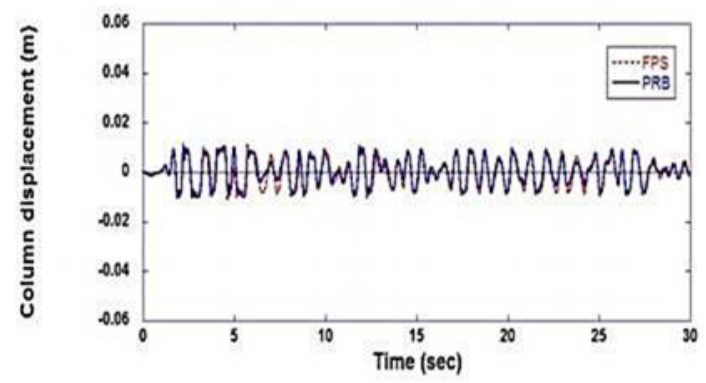

(d) Short Column Displacement

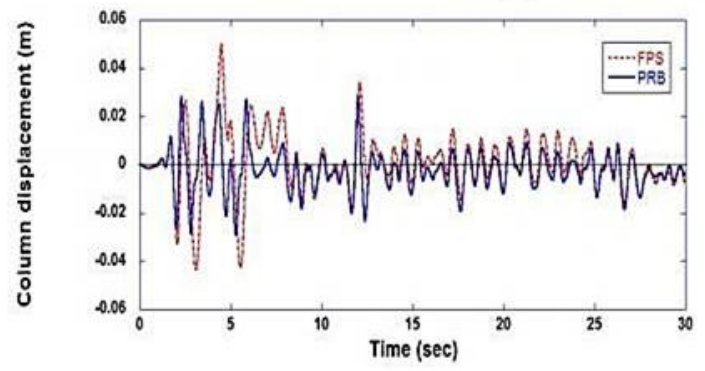

(e) Long Column Displacement

Figure 7. Time History of PRB and FPS under El Centro Earthquake

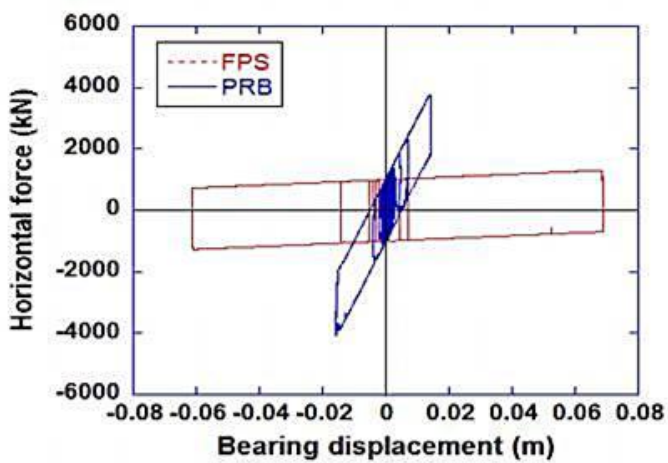

(a) Bearing in Short Column

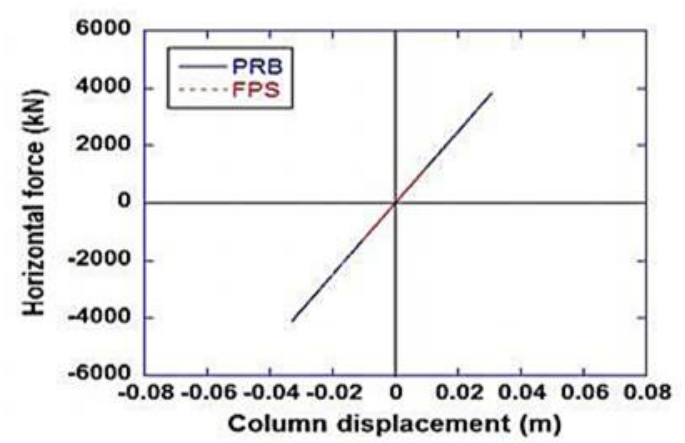

(c) Short Column

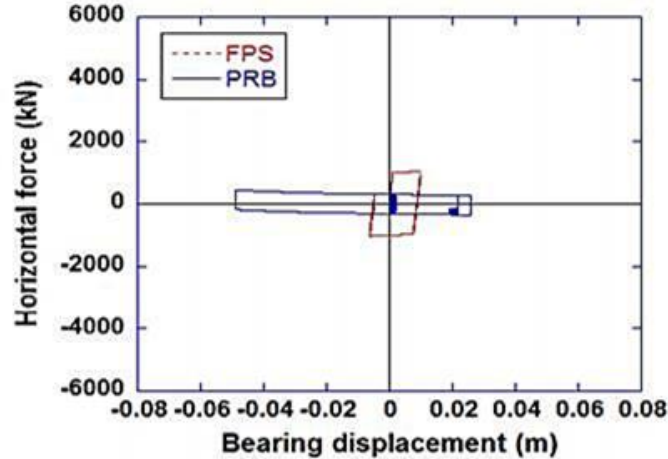

(b) Bearing in Long Column

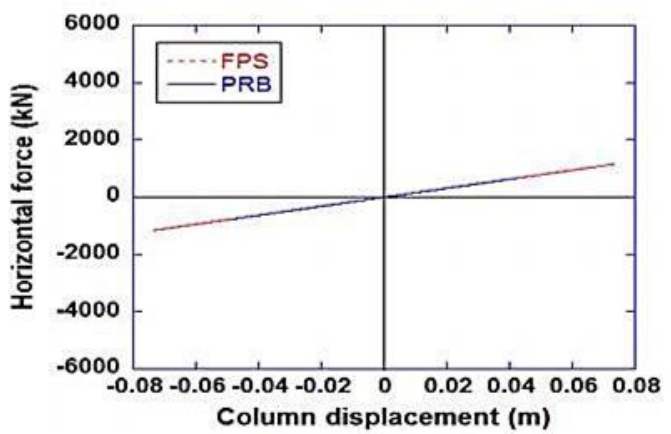

(d) Long Column

Figure 8. Hysteretic Loop of PRB and FPS under Northridge Earthquake 


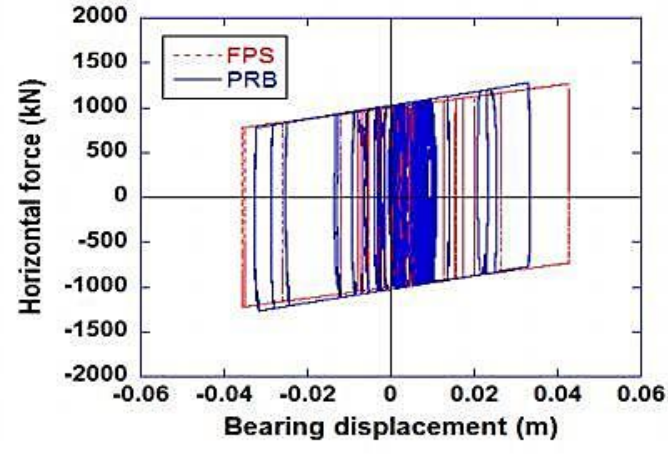

(a) Bearing in Short Column

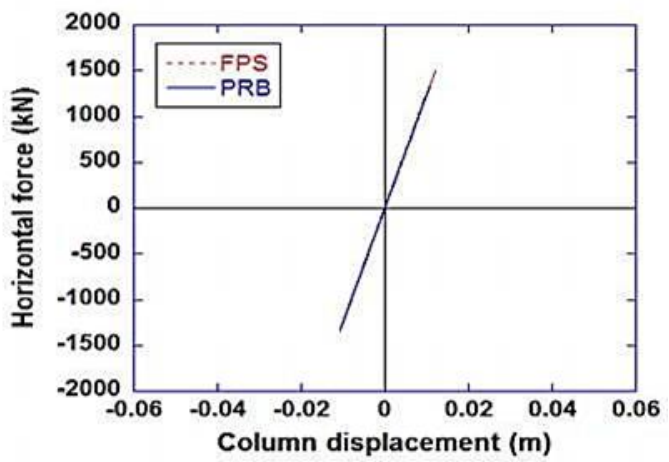

(c) Short Column

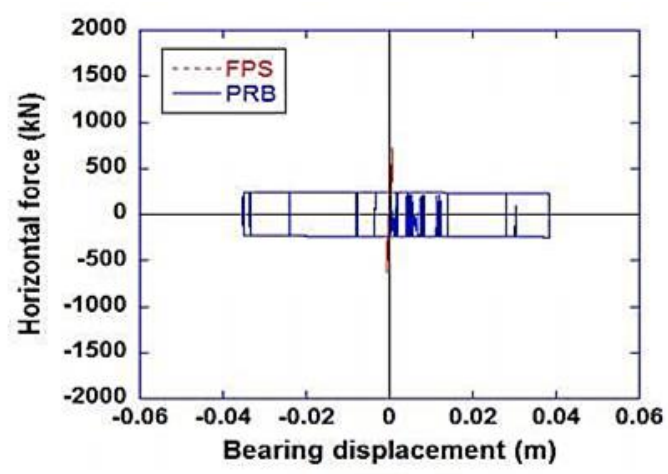

(b) Bearing in Long Column

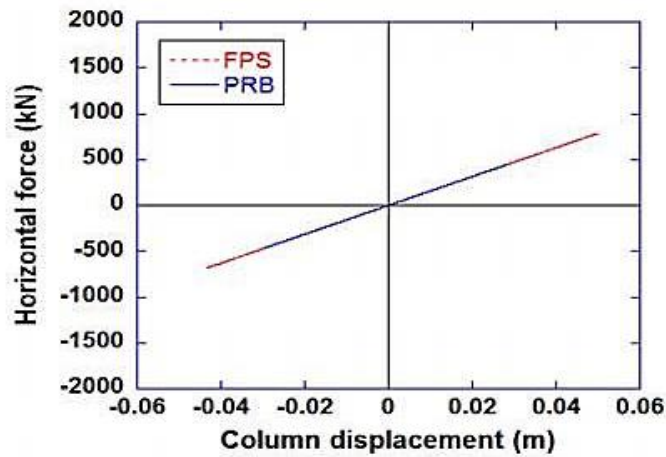

(d) Long Column

Figure 9. Hysteretic Loop of PRB and FPS under El Centro Earthquake

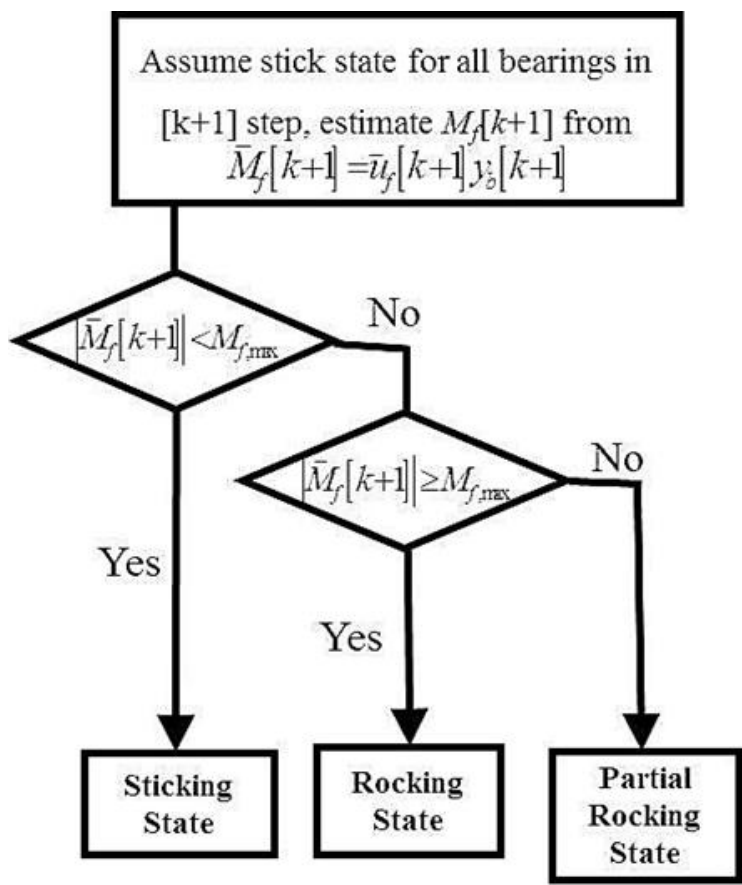

Figure 10. Analysis Process 


\section{Conclusions}

The PSO-SA hybrid searching method is used to find out the optimal design parameters of the PRB and FPS. Observed from the analytical results, the PSO-SA can obtain effective isolation effect of the PRB and FPS bearing parameters. However, some structural responses are not satisfactory because in this research two different analysis for the seismic isolation system and for the bridge structure are used. Non-linear analysis is used in the seismic isolation system and linear analysis is in the bridge structure. But, compared with the FPS, generally PRB can effectively suppress the deck displacement under both near and far-fault earthquakes. For the future research, it is suggested to consider the non-linear behavior of bridges, namely, non-linear analysis to achieve more realistic results for the structure response.

\section{References}

[1] Asher, J. W., Hoskere, S. N., Ewing, R. D., Van Volkinburg, D. R., Mayes, R. L., and Button, M. (1995). Seismic performance of the base isolated USC University Hospital in the 1994 Northridge earthquake. ASME-PUBLICATIONS-PVP, 319, 147-154.

[2] Bozorgnia, Y., Mahin, S. A., and Brady, A. G. (1998). Vertical response of twelve structures recorded during the Northridge earthquake. Earthquake Spectra, 14(3), 411-432.

[3] Çelebi, M. (1996). Successful performance of a base isolated hospital building during the 17 January 1994 Northridge earthquake. The Structural Design of Tall and Special Buildings, 5(2), 95-109.

[4] Fujita, T. (1998). Seismic isolation of civil buildings in Japan. Progress in Structural Engineering and Materials, 1(3), 295-300.

[5] Kelly, J. M. (1986). Aseismic base isolation: review and bibliography. Soil Dynamics and Earthquake Engineering, 5(4), 202-216.

[6] Kelly, J. M. (1998). Seismic isolation of civil buildings in the USA. Progress in Structural Engineering and Materials, 1(3), 279-285.

[7] Koh, C. G., and Kelly, J. M. (1988). A simple mechanical model for elastomeric bearings used in base isolation. International journal of mechanical sciences, 30(12), 933-943.

[8] Lu, L. Y., and Hsu, C. C. (2013). Experimental study of variable-frequency rocking bearings for near-fault seismic isolation. Engineering structures, 46, 116-129.

[9] Martelli, A., and Forni, M. (1998).Seismic isolation of civil buildings in Europe. Progress in structural engineering and materials, 1(3), 286-294.

[10] Matsagar, V. A., and Jangid, R. S. (2006).Seismic response of simply supported base-isolated bridge with different isolators. International Journal of Applied Science and Engineering, 4(1), 53-69.

[11] Naeim, F., and Kelly, J. M. (1999). Design of seismic isolated structures: from theory to practice. John Wiley \& Sons. 